\title{
Desafios para pensar a inovação em tempos de crise: uma cartografia no CAPS
}

\author{
Challenges for thinking about innovation in times of crisis: cartography at CAPS
}

\author{
Cynthia dos Santos Monteiro' e Patrícia Oliveira Lira
}

Resumo: Esse relato de pesquisa foi produzido a partir da dissertação construída junto ao Mestrado Profissional de Psicologia - Práticas e Inovação em Saúde Mental/UPE a partir do desejo de produzir possibilidades inovadoras no cuidado considerando a experiência enquanto trabalhadora de saúde mental e gerente clínica de um Centro de Atenção Psicossocial. Retomamos o movimento da Reforma Psiquiátrica Brasileira para circunscrever o próprio CAPS e rastreamos um descompasso entre o cenário nacional e sua vivência em Ipojuca/PE onde esse dispositivo ainda se impõe como uma inovação para o cuidado em liberdade. Diante do atual redirecionamento da Política Nacional de Saúde Mental, cenário o qual contextualizamos como "crise", e suas conexões com o contexto municipal, essa pesquisa foi se modificando de uma desejada intervenção inovadora para a produção de mapas sobre as possíveis formas de resistência com o território. Assim, fizemos aliança com a cartografia de Deleuze e Guattari (2011) como método a fim de rastrear as capturas e linhas de fuga desses acontecimentos ao longo do percurso trilhado. Experimentando a micropolítica dos encontros, algumas estratégias foram operadas na direção de ampliar as conexões do CAPS com dispositivos da Rede de Saúde. Através desse trabalho se busca resistir a um modelo asilar e de exclusão.

Palavras-chave: CAPS; Micropolítica; Cartografia.
Abstract: This research report was produced based on the dissertation built within the Professional Master in Psychology - Program of Practices and Innovation in Mental Health at the State University of Pernambuco as part of my aspirations in contributing to produce innovative possibilities in mental health care considering my experience as a mental health public worker and clinical manager of a Psychosocial Care Center (CAPS). We reviewed the movement of the Brazilian Psychiatric Reform to marks out the CAPS itself and we identified a mismatch between the national scenario and the current experience in the municipality of Ipojuca/PE, where this public service still imposes itself as an innovation for health care in freedom. Given the recent current changes of the National Mental Health Policy, a scenario which we have named as "crisis", and its connections with the municipal context, this research has moved from having as its goal the outline of an innovative intervention to mapping possible forms of resistance in the territory we inhabit. Thereby, we have made an alliance with the cartography of Deleuze and Guattari (2011) as a method to track the captures and escape lines of these events along the trail. Experiencing the micropolitics of the encounters, some strategies were operated in order to broaden connections of the CAPS with Healthcare network. Through this work we seek to resist to a model of isolation and exclusion that has been gaining presence in the public agenda, setting the CAPS as the emblem of mental health care in freedom.

Keywords: CAPS; Micropolitics; Cartography.

\footnotetext{
1 Psicóloga e bacharel em psicologia pela Universidade Federal de Pernambuco. Mestre em Psicologia - Práticas e Inovação em Saúde Mental pela Universidade de Pernambuco, Brasil(2019). Atualmente psicóloga da Prefeitura Municipal de Recife , Brasil. E-mail: cysmonteiro@gmail.com

2 Psicóloga e bacharel em psicologia pela Universidade Federal de Pernambuco. Mestre em Psicologia Clínica pela Universidade Católica de Pernambuco e Doutora em Psicologia pelo Université Paris 13 (Paris-Nord) - Campus de Villetaneuse, França(2010). Professora Adjunto da Universidade de Pernambuco, Brasil. E-mail: patricia.lira@upe.br
} 


\section{Introdução}

Esse relato de pesquisa foi produzido a partir da inserção do Mestrado em Psicologia - Praticas e Inovações em Saúde Mental - UPE tendo como ponto de partida o desejo de construir possibilidades inovadoras no cuidado a partir da experiência enquanto psicóloga, trabalhadora de saúde mental e gerente clínica de um Centro de Atenção Psicossocial - CAPS- situado no município de Ipojuca em Pernambuco.

Retomamos que o CAPS é um dispositivo oriundo da Reforma Psiquiátrica Brasileira a qual, inspirada na proposta italiana, foi abrindo passagem a partir da década de 1970 e contou com amplo apoio de vários seguimentos da sociedade, produzindo um processo gradativo de desinstitucionalização da atenção à saúde mental. No nosso contexto, desinstitucionalização vai além da reorganização dos serviços de saúde indo ao encontro de uma ruptura com o paradigma da psiquiatria tradicional, como desconstrução do saber psiquiátrico que sustentava a lógica manicomial vigente na sociedade, apontando para a relação mecânica de causa-efeito no diagnóstico da loucura (Rotelli, 1990; Amarante, 2011).

Assim, o CAPS caracteriza-se por ser um serviço de caráter aberto e comunitário, composto por equipe multiprofissional sob a égide da ótica interdisciplinar, que realiza prioritariamente atendimento às pessoas com sofrimento mental, incluindo aquelas com necessidades decorrentes do uso de álcool e outras drogas, em sua área territorial, seja em situações de crise ou nos processos de reabilitação psicossocial, sendo substitutivos ao modelo asilar (Brasil, 2011).

Dessa forma, cada serviço tem a missão de produzir suas estratégias de cuidado em liberdade considerando que a manifestação de sofrimento psíquico ocorre de modo singular e que o objetivo da intervenção psicossocial não é mais o retorno a uma pretendida normalidade externa à pessoa, como no modelo psiquiátrico tradicional, esse campo é convocado à reinvenção (Milhomem \& Oliveira, 2017).

Faz-se indispensável lembrar que a implantação dos CAPS, assim como dos demais equipamentos, ações e iniciativas necessárias para uma Reforma Psiquiátrica efetiva, diz respeito essencialmente à elaboração e à implementação de políticas públicas em todos os níveis e esferas de governo (Lobosque, 2017). Assim, cada município vem fazendo essa caminhada rumo à efetivação do SUS e da Reforma Psiquiátrica de acordo com seu contexto social, econômico e cultural. Ressaltamos que um dos princípios, do SUS, a descentralização, garante a passagem de um sistema centralizado na União para um modelo de governos municipais, com importante ganho de autonomia no campo da saúde. Porém "as condições para que a descentralização atenda a garantia do acesso universal às ações e serviços de saúde e da atenção integral de acordo com as necessidades e demandas da populaç̧ão não estão asseguradas, apresentando resultados contraditórios no território nacional" (Pinafo, Carvalho \& Nunes, 2016, p.1512).

Em Pernambuco, um dos primeiros Estados brasileiros a instituir uma legislação própria promulgando a Lei Estadual n¹1.064/1994 que dispunha sobre a substituição progressiva dos Hospitais Psiquiátricos por uma rede de atenção integral à saúde mental, a assistência ainda ficou muito restrita à sua capital. Esse aspecto denuncia uma fragilidade na efetivação do modelo no Brasil que acontece principalmente em municípios de pequeno porte no Brasil.

No município de Ipojuca, mesmo diante da grande relevância na economia estadual, curiosamente até 2012 ainda não se conhecia uma política substitutiva de hospital psiquiátrico. A cidade faz parte da Região Metropolitana do Recife desde 1994 e tem como principais fatores econômicos o turismo e Complexo Portuário Industrial de Suape em seu território, que há pelo menos 2 décadas, movimenta economicamente o município (Mattoso, 2013).

Mesmo assim podemos dizer que não havia espaço para as pessoas que necessitavam de atenção referente a sua saúde mental. A ausência do CAPS na rede de saúde municipal vinha acarretando a procura por esses serviços em municípios vizinhos e 0 apelo ao recurso da internação em hospital psiquiátrico como forma de buscar respostas a tais demandas.

Apenas com 0 advento da criação de uma linha específica de financiamento legitimada pela Portaria Ministerial no 336 de 19 de fevereiro de 2002, que define suas diversas modalidades definidos por ordem crescente de porte/complexidade e abrangência populacional, que os CAPS passaram a ganhar força e a se expandirem no Brasil. Nessa década, diversos municípios foram impulsionados à implantação desses serviços para que pudessem atender pessoas em sofrimento psíquicos sem retirá-los de seu meio e do convívio em sociedade.

0 desejo de produzir um outro cuidado em Saúde Mental no município, aliançado com a Reforma Psiquiátrica, deu abertura para implicação da equipe no processo de criação do novo serviço, buscando produzir novos ol hares para o sofrimento psíquico. Enquanto equipe, desde antes da implantação vínhamos num esforço de conectar os atores sociais de Ipojuca ao CAPS enquanto movimento micropolítico de produção de cuidado num processo coletivo e não apenas enquanto dispositivo fruto de uma políitca pública instituída de modo pré-formatado.

Assim, embora tenhamos avançado no terreno macropolítico, ainda enfrentamos na micropolítica do cotidiano os riscos da reprodução da lógica manicomial nos novos dispositivos que compõem a Rede de Atenção Psicossocial, na qual se inclui o CAPS, construídos para romper a histórica lógica tutelar de atenção à pessoa portadora de sofrimento psíquico.

Mesmo durante a pesquisa, esse vinha sendo o principal desafio do serviço, pois esse CAPS nasceu como obrigação de governabilidade, já que mesmo diante dos percalços municipais, pode-se dizer que no contexto nacional ainda havia estímulo para a abertura de novos serviços substitutivos aos manicômios por meio das políticas progressistas em Saúde do governo daquele momento.

Ainda, chamamos atenção ao contorno dado, ao longo deste estudo, aos conceitos de macro e micropolítica - ou, também, molar e molecular a qual fazemos aliança através do no pensamento de Deleuze e Guattari (2011). A ordem molar corresponde às estratificações que delimitam objetos, sujeitos, representações e seus sistemas de referência. Nesta perspectiva delineiam uma dinâmica do social que tendem ao controle e à homogeneização. Por outro lado, a ordem molecular possui maior fluidez e é a das transiç̧ões de fases, do que pode vir ser, ou seja, dos devires e são da natureza de uma micropolítica que escapam ao controle dos sistemas molares macropolíticos (Deleuze \& Guattari, 2011).

Sendo assim, podemos dizer que o plano do instituído (molar) cumpre também um papel histórico importante porque vigora para ordenar as atividades sociais essenciais para a vida coletiva, no entanto que deve permanecer aberto às transformações com que o instituinte (molecular) acompanha o devir social (Barembllit, 2012). A indissociabilidade desses planos compõe o coletivo 
de forças no qual vivenciamos a Reforma Psiquiátrica nos diferentes contextos do Brasil. Sendo ao mesmo tempo força revolucionária na micropolítica, mas também capturado na macropolítica.

\section{O impacto do recrudescimento neoliberal no âmbito da política pública de saúde mental no contexto macropolítico brasileiro}

Para construção de uma rede de serviços no âmbito do SUS, as relações institucionais ultrapassam os entes públicos e envolvem uma variedade de arranjos e acordos entre as esferas públicas e privadas (instituições e sujeitos) para garantia de ações e serviços de saúde que não são suficientemente ofertados pela rede pública e precisam ser complementados. Trata-se de um assunto melindroso, mas importante, visto que "esse binômio materializa, no Brasil, impasses histórico-sociais, como a concentração de renda e o predomínio de interesses de grupos e setores econômicos" (Heimann, Ibanhes, Boaretto \& Kayanoet, 2010, p. 208).

No cenário nacional, após o impeachment da presidenta Dilma Rousseff em 2016, houve mudanças da gestão e da prioridade dada à Saúde Mental que apontam para um retrocesso e traçando um caminho que, especialmente após as eleições de 2018, tem colocado em risco princípios básicos do SUS e da Reforma Psiquiátrica (Amarante, 2018). Como exemplos, podemos citar que a Comissão Intergestores Tripartite aprovou a Portaria 3588/2017 que reinsere 0 hospital psiquiátrico como ponto de atenção legítimo para assistência à pessoa em sofrimento mental, apesar de já haver leitos em hospitais gerais pactuados na Rede de Atenção Psicossocial-RAPS 3088/2011 para fins de hospitalização nos casos que demandam esse tipo de intervenção. Amarante (2018) observa que essa resolução praticamente resgata o modelo manicomial e dá início à desmontagem de todo o processo construído ao longo de décadas no âmbito da Reforma Psiquiátrica brasileira.

Diante das rupturas no contexto macropolítico brasileiro é importante ressaltar especialmente a questão do orçamento:

A remanicomialização da saúde mental, com 0 asseguramento e enorme investimento financeiro no reajuste de recurso do Governo Federal, que aumenta o valor da diária dos manicômios em média 65\%. Em contrapartida, não há aumento do repasse para os CAPS em suas diferentes modalidades desde 2011, 0 que intensifica a precarização do equipamento e gera dificuldades operacionais no cotidiano desses serviços, ou seja, o hospital psiquiátrico, que na lógica da Reforma sofreu uma amortização gradativa, sendo excluído da RAPS, retorna com força total e muito dinheiro (Guimarães \& Rosa, 2019, p.123).

Ainda, a Portaria delineando novas diretrizes de ações foi reforçada em 6 de fevereiro de 2019 através da Nota Técnica no 11/2019-CGMAD/DAPES/ SAS/MS aprofundando as mudanças propostas, introduzindo uma lógica onde não se considera mais serviços como sendo substitutos de outros e coloca 0 hospital psiquiátrico como espaço estratégico de cuidado. A mesma nota foi retirada do site do Ministério da Saúde para reavaliação, após diversas manifestações de movimentos sociais e entidades ligadas ao movimento da
Luta Antimanicomial, mas deixou claro um processo de profundo de violação dos direitos no que tange o cuidado em liberdade.

Dessa forma, a agenda da contrarreforma, suas Portarias e as ações orçamentárias anunciadas, vem avançando contra à Saúde Mental. Relembramos que desde 2016 já vivemos com a imposição da Emenda Constitucional 95 que vigorará pelos próximos vinte anos e que instituiu um "novo regime fiscal" para a Seguridade Social da União, ou seja, congela os recursos para a ampliação e qualificação dos equipamentos do Sistema Único de Saúde.

Sendo assim, os municípios acabam vivenciando uma realidade na qual o SUS se propõe como universal, mas vive de cotas e limites, sendo difícil conseguir mantê-lo como um direito público. E os direcionamentos atuais demonstram buscar enfraquecer a construção de uma Rede Pública de base comunitária que tem como sua premissa fundamental o cuidado em liberdade e as estratégias de reabilitação e inclusão social (Pinafo, Carvalho \& Nunes, 2016)

Esse conjunto de mudanças que apontam para um recrudescimento da lógica asilar referente à Política de Saúde Mental constitui o que caracterizamos como crise nesse campo e ante as rupturas institucionais no contexto sociopolítico nacional (que produzem ressonâncias nos municípios). E, portanto, essa conjuntura política nacional tem nos colocado diante de um cenário em que a política de Saúde Mental tem sido questionada e com ela a efetividade dos CAPS. Num município que ainda não acessava a potência dos serviços substitutivos, como é o caso dessa pesquisa, isso vem acarretando numa distorção ainda mais grave da possibilidade de cuidado aberto e territorial.

Outro entrave que se impõe para a produção do cuidado em liberdade se refere à diversidade de formas de contratação dos profissionais e rotatividade deles nos serviços vem fragilizando consideravelmente a continuidade das intervenções psicossociais.

Fazemos aliança com o pensamento de que "qualquer que seja 0 programa terapêutico que se crie [...], ele será profundamente sensível aos modos estruturais e conjunturais de organização do dispositivo institucional em que ou por meio do qual é executado" (Costa-Rosa, 2000 como citado em Milhomem \& Oliveira, 2007, p.106). E mesmo reconhecendo que se somam à questão da precarização do trabalho, outros aspectos tais como: número reduzido e baixo investimento em qualificação dos trabalhadores, condições internas desfavoráveis (ausência ou insuficiência de materiais e instrumentos), ausência de plano de cargos e carreiras, entre outros (Milhomem \& Oliveira, 2007), consideramos que o concurso público representa um aliado para fortalecer as políticas públicas, no sentido de continuidade, processualidade histórica e cultural de um corpo técnico num determinado território.

Apenas a partir da Constituição de 1988, o concurso público se tornou obrigatório para cargo e emprego público, contudo, a Lei de Responsabilidade Fiscal de 2000, pode ter desencorajado a realização de concursos públicos. Essa Lei tem como objetivo principal o controle das contas públicas com redução de despesas com o funcionalismo público, estipulando um limite para a União de $50 \%$ da receita corrente líquida com despesas de pessoal do Estado e, para os estados e municípios, 60\%. Portanto, de acordo com Druck (2016), isso pode ter incentivado a terceirização, uma vez que as despesas com a subcontratação de empresas e com a contratação temporária, emergencial e de comissionados não são computadas como despesas com pessoal, de acordo com a mesma Lei.

A partir de então, criou-se e expandiu-se as modalidades de terceirização na esfera pública, principalmente a partir de 2015, com decisão do Supremo 
Tribunal Federal (STF), foi validada como constitucional e sendo liberado, dessa forma, a terceirização para todos os serviços essenciais sob responsabilidade do Estado: saúde, educação, cultura, ciência e tecnologia, desporto/lazer e meio ambiente. Desse modo, parte dos serviços públicos é realizada não mais pelo servidor público, profissional concursado, mas pelos mais distintos tipos de trabalhadores, em geral empregados de forma precária, com contratos por tempo determinado e sem os mesmos direitos que o funcionário público.

A partir do CAPS dessa pesquisa, sentimos que essas diversas formas de contratação trazem prejuízos à formação de servidores comprometidos com o SUS e com a Reforma Psiquiátrica, devido à precariedade do vínculo e/ou pela rotatividade e compartilhamos com Milhomem e Oliveira (2007) que se torna indispensável considerar também a precarização do trabalho em saúde como algo que influenciará fundamentalmente os resultados do trabalho terapêutico nos dispositivos de atenção à saúde mental.

Na dimensão macropolítica, a desvalorização do profissional concursado parece operar também como um desmonte ao funcionamento da saúde enquanto política pública. Talvez não por acaso, em 2012 num contexto social macropolítico onde ainda se valorizava a possibilidade de fortalecimento de políticas públicas sociais, esse CAPS é concebido e instaurado no município, enquanto, no contexto atual, a maioria dos profissionais não são mais concursados e não parece haver preocupação em realizar nova contratação através de vínculo estatutário no município.

Sendo assim, essa pesquisa foi se modificando ao longo dos dois anos de sua realização, de modo a se deslocar de uma possível intervenção inovadora, visando avançar na perspectiva antimanicomial no município por meio da consolidação do CAPS, para o "retorno" ao esforço (histórico) frente a cultura excludente da política asilar materializada na figura do manicômio.

\section{Método}

Diante desse contexto e partilhando do pensamento que toda pesquisa é uma intervenção e toda intervenção em saúde é sempre uma atitude clínico-política, uma indissociabilidade entre a produção de conhecimento e a transformação da realidade (Passos \& Barros, 2009). Nessa perspectiva, tomamos como inspiração a cartografia proposta por Deleuze e Guattari (2011) como método que não se restringe a um sistema de procedimentos em pesquisa, mas diz respeito ao modo como o pensamento se opera em profunda conexão com a produção de territorialidades, a partir da implicação com fluxos intensivos na processualidade dos encontros.

A cartografia como inspiração metodológica nesse estudo foi fundamental para dar passagem aos diferentes caminhos percorridos ao longo do mestrado, possibilitando que o projeto de pesquisa, o qual foi submetido ao Comitê de Ética e aprovado sob o CAAE: 26188819.0.0000.5191, possa ter sido trilhado mesmo diante das alterações entre a proposta inicial para 0 resultado final dessa dissertação.

Ao retomarmos a etimologia da palavra metodologia percebemos a noção de um caminho (hódos) determinado pelas metas (metá) que são estabelecidas para que o próprio caminhar seja percorrido (Costa, 2014). No entanto "a cartografia propõe uma reversão metodológica: transformar 0 méta-hódos em hódos-metá" (Passos et al, 2009, p.11) e dessa forma 0 processo vai se compondo a partir do percurso trilhado.

Diferentemente do mapa geográfico que faz uma representação de um todo estático, a cartografia é um mapa fluido que acompanha movimentos e, portanto, tem noção diferenciada de pesquisador, produto e também processo de produção (Deleuze \& Guattari, 2011). Seguindo as pistas de noção de território para Deleuze e Guattari, entendemos que esse não se reduz a um espaço físico de estabilidade e organização, mas, sim, a um espaço relacional e em constante movimento que envolve sentimentos e forças que ali se produzem compondo um território existencial.

Uma ferramenta de essencial importância em todo o processo foi o diário de campo, pois nele não só foram registradas as experiências e afetações ao longo dos encontros durante a pesquisa, como também permitiu acompanhar as transformações do próprio território existencial da pesquisadora ao longo do estudo, possibilitando reviver al gumas situações ao longo de todo o processo.

0 diário de campo foi nesta pesquisa um dispositivo de (in) formação, uma forma de trabalho/pesquisa que permitiu a consulta nos arquivos das ideias e afetações que nele estavam. Em vários momentos torna-se difícil vivenciar os vários passos da pesquisa e fazer as notas de campo ao mesmo tempo, em alguns momentos pode até causar desconforto para os envolvidos. Assim, criar notas mentais e termos à mão um pequeno bloco para registrar as palavras chaves pode ser um recurso de grande apoio. Como a proposta é acompanhar movimentos e processos aos quais o pesquisador está inevitavelmente ligado, o diário pode ser uma ferramenta capaz de contribuir com o pesquisador para reler sua própria atividade em campo, o qual é pensado tanto como um campo nos quais as atividades específicas da pesquisa se desenvolvem, quanto no campo da vida onde a vida e o conhecimento se processam (Oliveira, 2014).

Dessa forma, no contexto aqui pesquisado, o CAPS se põe como um devir, como uma conexão que se abre para a criação de novas subjetividades, de novos territórios e como uma inovação técnico-assistencial no município, como um dispositivo ainda em processo de consolidação. Entretanto, esse movimento intenso de reinvenção cultural e política tem sido atravessado pelas contradições impostas pelo cenário macropolítico nacional, ensejando a necessária reflexão crítica a partir desta pesquisa. Lançados na cartografia, buscamos produzir mapas sobre as linhas de resistência dos atores que compõem 0 CAPS na produção do cuidado em liberdade e nos encontros produzidos com a RAPS de Ipojuca tomados como disparadores para a produção de desvios diante do processo de crise que vem afetando o campo da Saúde Mental atualmente.

Como possibilidades de intervenção, fez-se necessário retomar a ideia de rede para compor essa trincheira de resistência, sendo o CAPS nosso ponto de contato nesse percurso. Dessa forma, como resultado desse processo de pesquisa, trouxemos as tentativas de operar aberturas para composição do exercício micropolítico onde a clínica passa a ser efeito de uma ação ética, estética e política de resistência frente aos agenciamentos massificantes da máquina capitalística.

Nessa pesquisa voltamos o nosso olhar mais atentamente para os profissionais de saúde a fim de que se reconheçam enquanto protagonistas das políticas e possam contribuir junto aos usuários dos serviços nessa retomada do serviço de saúde enquanto espaço aberto a multiplicidades.

A possibilidade de produzir desvios e bifurcações depende do nível de composição do serviço com o território e por isso nos pareceu fundamental novas tentativas de somar forças. Ao longo do processo de pesquisa, foi sendo percebido que havia um desejo presente que tinha dificuldade em dar vazão 
devido tantas tentativas e aos entraves ao longo do caminho: tecer redes.

Nesse sentido fez-se a tentativa de produzir a partir desse trabalho uma busca de subverter essa Rede "capturada por sistemas normativos de significação da realidade, que serializam as práticas de cuidado quebrando a lógica das singularidades existentes tanto no trabalhador quanto no usuário" e produzir desvios para criação de outra que "se organize em conexões e fluxos contínuos de cuidado, onde são produto e ao mesmo tempo produtoras da ação dos sujeitos singulares que se colocam como protagonistas em um determinado serviço de saúde" (Franco, 2006).

Dessa forma, diante da ausência de espaços de encontro para profissionais de saúde, buscamos a partir do CAPS compor essa relação necessária em rede e buscar investir mais na micropolítica dos afetos, sendo esses os desvios possíveis no contexto dessa pesquisa.

\section{Resultados}

Como intervenção possível desse trabalho, buscamos mapear as tentativas de conectar redes. Ressalto como marcadores desse relato as tentativas de construção do trabalho em rede gerando encontros com os profissionais, mais especificamente com a Atenção Básica devido à possibilidade de abertura desse campo nesse momento do município e por sua dimensão também comunitária, a partir da proposta de matriciamento e do Fórum Saúde Mental. Assim buscamos investir na micropolítica, não como uma macropolítica reduzida, mas como processo de investir nos encontros, nos afetos (Merhy, 2002).

Compondo nosso mapa, chegamos aos dispositivos da atenção básica que integram a Rede de Atenção Psicossocial no âmbito da Saúde. Esclarecemos de antemão que não foi possível ainda envolver outros atores das demais políticas públicas a fim de compor um cuidado intersetorial, sendo uma questão relevante para problematizar como o lugar da Saúde no município vem se compondo num campo próprio. Contudo a problematização desse fluxo entre as Políticas em Ipojuca merece ser foco de outras pesquisas posteriormente.

Fazendo recorte sobre a Atenção Básica, porta de entrada para o acesso ao Sistema Único de Saúde, somam dezenove USF's- unidade de saúde da família, uma UBS - unidade básica de saúde, e uma equipe de PACS - programa de agentes comunitários de saúde, que perfazem aproximadamente $60 \%$ de cobertura de seu território e duas equipes de NASF_ — núcleo de apoio à saúde da família.

Consideramos que a produção do cuidado em saúde mental depende de todos os componentes da RAPS (sem reduzir-se a eles), e a ampliação dessa rede representa uma maior riqueza nas possibilidades do cuidado a partir do próprio CAPS.

Apesar do fluxo ainda incipiente entre os serviços que compõem a Rede de Saúde de Ipojuca, a equipe do CAPS tem buscado ao longo dos anos se aproximar dos outros atores que compões o território por meio da articulação para 0 cuidado às pessoas que frequentam o serviço, bem como através de atividades em datas ou campanhas relacionadas ao campo da saúde mental. Em todas as oportunidades de ir além das paredes físicas do CAPS, buscamos dialogar sobre o que é esse dispositivo e como o cuidado deve ser integral junto a outros parceiros.

Reconhecendo o cenário de disputas e diversidade de compreensões sobre saúde no município, buscamos abrir caminhos para a discussão dos diferentes modos de conceber suas práticas em saúde com o território. Segundo Mehry e Feuerwerker (2016) essas oportunidades podem se dar através de "espaços coletivos para reflexão sobre o processo de trabalho, de modo que os diferentes atores possam conhecer o conjunto do trabalho que é desenvolvido e estabelecer um acordo acerca do para que serve o trabalho desse coletivo" (p. 69).

Desejosos de produzir encontros a partir do CAPS buscamos acessar gestores e outros profissionais que compõem a rede de cuidado no município e esses encontros foram dando passagem a possibilitar a construção de novos desvios em conjunto com esses atores. Foram produzidos ao longo desse estudo, espaços para trocas sobre as estratégias de Matriciamento, sendo que esse processo ainda está em construção, não havendo um delineamento instituído com o término desse estudo, mas o processo foi inicialmente discutido no mês de junho com os profissionais da rede num evento da Atenção Básica proposto a partir da parceria da gerência do CAPS com a coordenação de Saúde Mental.

Esse evento foi um gatilho para discussão e rastreamento das dificuldades colocadas pelos parceiros na produção coletiva o cuidado. Muitas considerações se remeteram ao suporte do CAPS para medicação dos usuários que frequentam as USF's o que parecia se remeter à lógica do olhar para os sintomas e o cuidado centrado na figura do médico. Foram apontadas muitas dúvidas sobre 0 assunto e explicitado ser esse um dos fatores de desresponsabilização no cuidado à saúde mental.

Também abrimos passagem para construção do Fórum Municipal de Saúde Mental que teve dois encontros: no início do mês de junho com 0 tema de Saúde Mental, o cuidado no território e a importância da RAPS e posteriormente em setembro por meio da campanha de Prevenção ao Suicídio.

0 formato de fórum é muito utilizado para viabilizar uma ampla discussão, debate de ideias e opiniões sobre temas específicos, nesse caso Saúde Mental. Foi produzido num formato mais simples, que consistiu em uma apresentação o breve, seguida de momento para perguntas e comentários. Acompanharam esse Fórum principalmente profissionais da Atenção Básica e da parte da equipe do CAPS e Residência Terapêutica. Mais uma vez, as discussões e afetações foram registradas em diário de campo para serem novamente vivenciadas em momento posterior.

Nas duas experimentações de trocas a partir desse espaço rastreamos que muitos das afecções e dificuldades vivenciadas pelos profissionais da Atenção Básica estão em conexão com os profissionais do CAPS, porém cada qual lida com seus desafios isoladamente. Torna-se importante também aprender a lidar com o desconforto que pode surgir entre os trabalhadores, sobretudo quando não estão habituados a refletir sobre si mesmos e sobre 0 seu trabalho (Peduzzi, 2003).

Foi discutida a importância da RAPS para o cuidado no território, retomando os princípios da Reforma Psiquiátrica. Foi também abordado brevemente o cenário do redirecionamento da Política de Saúde Mental o que gerou tensões acerca de posicionamento político partidários.

\section{Discussão}

Colocamos em relevo nessa pesquisa o desafio de rastrear os fluxos das formas molares e forças moleculares na produção de saúde, sendo que talvez essa tenha sido a principal composição enquanto cartógrafa. 
Nessa perspectiva, estar na posição de cartógrafa nos permitiu uma implicação no exercício de experimentar a sustentação da abertura de pensamento para acessar o que foi se operando no processo de pesquisar, sem conceitos prévios, como possibilidades de construção de conhecimento. E dessa forma pudemos rastrear algumas pistas para compor o nosso mapa.

Buscamos assim mapear a tentativa de tessitura de uma rede de alianças em torno do cuidado, como uma das dimensões essenciais do nosso processo de trabalho, e produzir possibilidades de ampliá-Io no território a partir da experimentação de novos encontros. A construção de um mapa desse processo que foi vivenciado em meio à crise da Política de Saúde Mental, num município que sequer havia acessado a potência do cuidado integral com 0 território às pessoas em sofrimento mental. Mas apontou pistas para que sigamos construindo juntos: profissionais, usuários, familiares e comunidade as o trabalho no território se configura como um diálogo permanente com os valores que produzam sentidos de vida.

Esse momento de crise parece estar circunscrevendo os serviços em sua luta para manter-se funcionando diante de tantas lacunas, porém capturados pelo instituído o que parece estar bloqueando algumas possibilidades de composição com o território de um serviço que na sua essência é eminentemente comunitário.

0 cuidado ainda se configura de forma verticalizada no município, de forma geral, e rastreamos que o próprio CAPS também vem fazendo parte dessa captura, pois vem lutando para tentar existir enquanto macropolítica, porém não conta com o movimento micropolítico junto ao território. Acessamos que estamos sendo colocados e, mesmo sem nos dar conta, assumimos a oferta do cuidado à comunidade e não a produção de cuidado na sua potência klínica.

Essa klínica com k, como nos traz Baremblit (1998) para indicar 0 sentido da origem grega de clínica, como encontro de diferenças e produção de desvio, de transformação faz vizinhança com a Atenção Psicossocial justamente por sua concepção molecular de produção do novo. Considerando que sua construção se produz fundamentalmente no cotidiano, no plano da experiência produzida pela interação entre os trabalhadores de saúde e os usuários e das reflexões suscitadas pela prática, podemos dizer que o trabalho em saúde modifica e produz novas maneiras de relação entre os sujeitos e destes consigo mesmos. Compartilhamos com Campos (2000) de que 0 trabalho em saúde tem uma dupla finalidade: produzir saúde e, ao mesmo tempo, produzir sujeitos, ou seja, contribuir para a constituição dos próprios trabalhadores e dos usuários.

Por meio da experimentação desses espaços pudemos acessar a partir do CAPS que ainda há um sentimento de dificuldade no trabalho em rede no território, especialmente no olhar desse cuidado como possibilidade de maior autonomia. Tem sido difícil operar essa circulação da pessoa em sofrimento mental, pois ainda há a fantasia da instituição total do hospital psiquiátrico no município como lugar soberano para essa demanda, tendo sido transferida essa responsabilidade para o CAPS de forma igualmente totalitária. Ainda não se percebe, de forma geral, que os diversos pontos de atenção da Rede podem, cada qual a seu modo, contribuir para a tessitura desse cuidado.

Pode parecer banal pensar em promover encontros entre serviços da rede na atenção psicossocial, quando essa questão já está instituída enquanto Política, mas em Ipojuca esse processo ainda carece desse movimento instituinte e, portanto, se constrói como uma inovação, uma vez que até hoje o Centro de Atenção Psicossocial ainda vem sendo apontado como o serviç "dono" de qualquer demanda referente à saúde mental.
Esse pensamento ainda reverbera no imaginário local entre população e outros profissionais da rede de saúde e intersetorial e é possível, de acordo com Silva (2018), que a centralidade dos CAPS, induzida na portaria 336/02, como regulador das ações de Saúde Mental no território podem ter gerado o deslocamento do manicômio para esse dispositivo. Porém não era dessa centralidade que a atenção psicossocial se propunha, e sim, do sujeito em relação com seu território e laço social (Lobosque, 2007). Ea partir da instituição da RAPS desenvolve-se mais a lógica de que os CAPS não assumem essa centralidade do cuidado, mas sim passam a ser mais um ponto de atenção dentro dos diversos componentes dessa rede por onde o sujeito possa circular, diante de suas diferentes necessidades.

\section{Considerações finais}

Nesse percurso retomamos os princípios da Reforma Psiquiátrica como inspiração enquanto revolução molecular para produção de um cuidado em liberdade em Ipojuca. Acessamos, contudo, que o movimento da luta antimanicomial no município encontra-se em descompasso ao compararmos com o cenário nacional e tem contornos mais restritos à equipe do CAPS, uma vez que a implantação desse dispositivo dentro do âmbito da macropolítica buscou atender a uma obrigação governamental o que se configurou como uma captura para a vivência molecular de produção de saúde nesse território. A composição dessas forças se impôs como grande desafio desse estudo.

Toda trajetória desse CAPS até aqui foi marcada pela busca de reconexão com os princípios instituintes da Reforma diante da contradição que marca o modo como foi operada a chegada, em Ipojuca, disso que deveria ser uma conquista política e não uma concessão de governo. Em outras palavras, no caso da implantação desse CAPS, essa conquista se deu por meio de um movimento da equipe técnica sem contar com a população ou movimento social. Assim, podemos perceber que apesar da Política Nacional de Saúde Mental prever uma atenção descentralizada e com participação efetiva da comunidade, tendo como principal objetivo promover a qualidade de vida e a construção de novas e melhores condições humanas, ainda há um longo caminho a ser trilhado.

0 rastreamento das forças histórico-políticas acessou um campo político, de disputas de lógicas do cuidado em saúde. Contudo, buscar a produção do trabalho vivo na micropolítica também nos permite experimentar constantemente novas possibilidades nas intervenções, o que confere também uma dimensão estética a esse trabalho (como possibilidade da criação, da inventividade), sem esquecer que o mesmo também é norteado por premissas éticas pertinentes ao cuidado com a vida, vigentes, também, nos princípios do SUS e da Reforma Psiquiátrica (Godoy, 2014).

Não obstante, a remanicomialização da Política Nacional de Saúde Mental faz parte de um projeto geral de desmonte do Sus que segue tendências neoliberais baseadas no trinômio da austeridade, privatização e desregulamentação que, acentuadas pela grave crise econômica, ataca um dos princípios fundamentais da atenção integral à saúde. As conquistas no plano legal e nas políticas públicas de saúde mental parecem pouco sólidas, ao serem desafiadas por essa conjuntura política e econômica (Guimarães \& Rosa, 2019).

Portanto a sobrevivência da Reforma Psiquiátrica está atrelada a lutas políticas de hoje. Retomar os princípios reformistas produzirá na nossa prática cotidiana - lugar de resistência por excelência - o soerguimento de uma 
trincheira construída por trabalhadores, usuários, familiares e sociedade. Apesar do avanço na legislação brasileira, podemos destacar que esse caminho vem sendo percorridos com vários obstáculos, desde a estruturação de seus dispositivos técnico-assistenciais e, principalmente, a ruptura em relação à psiquiatria tradicional.

No âmbito da saúde mental, Bezerra Jr (2004), concebe o CAPS como lugar no qual as plurais expressões de sofrimento encontram um significado na história e desejo do indivíduo que sofre, da família do qual este faz parte, da comunidade na qual ele está inserido. 0 cuidado, nesse contexto, está vinculado à proposta de contribuir para uma vida coletiva, cujas existências individuais sejam mais interessantes, abertas e criativas - por mais que esta expressão seja imprecisa e aberta à discussão.

\section{Referências}

Amarante, P. (1995) Loucos pela vida: a trajetória da reforma psiquiátrica no Brasil. Rio de Janeiro: Fiocruz

Amarante, P; Nunes, M. O. (2018). A reforma psiquiátrica no SUS e a luta por uma sociedade sem manicômios. Ciência \& Saúde Coletiva, 23(6), 2067-2074. https://dx.doi.org/10.1590/1413-81232018236.07082018

Baremblitt, G.F. (1998). Introdução à Esquizoanálise. Belo Horizonte, MG: Instituto Félix Guattari.

Baremblitt, G. F. (2002) Compêndio de análise institucional e outras correntes: teoria e prática, 5ed., Belo Horizonte, MG: Instituto Felix Guattari (Biblioteca Instituto Félix Guattari; 2)

Barros, L. P., \& Kastrup, V. (2012). Cartografar é acompanhar processos. In Passos, E., Kastrup, V., \& Escóssia, L. (Orgs.). Pistas do método da cartografia: pesquisa-intervenção e produção de subjetividade. Porto Alegre: Sulina.

Bezerra Jr, B.C. (2004) 0 cuidado nos CAPS: os novos desafios. In: Albuquerque, P.; Libério, M. (orgs.). O cuidado em saúde mental: ética, clínica e política. Rio de Janeiro: Coordenação de saúde mental da secretaria municipal de saúde do Rio de Janeiro, p. 3-11.

Brasil, Ministério da Saúde. Secretaria de Atenção à Saúde. Departamento de Ações Programáticas Estratégicas. (2004) Saúde mental no SUS: os centros de atenção psicossocial.

Campos, G.W.S; Amaral, M.A. (2007) A clínica ampliada e compartilhada, a gestão democrática e redes de atenção como referenciais teórico-operacionais para a reforma do hospital. Ciência \& Saúde Coletiva, 12(4), 849 -859 https://doi.org/10.1590/S1413-81232007000400007

Costa, L. B. (2014) Cartografia: uma outra forma de pesquisar. Revista Digital do LAV - 7 (2), 66 - 77 http://dx.doi.org/10.5902/1983734815111.

Deleuze, G. \& Guattari, F. (2011) Mil Platôs: capitalismo e esquizofrenia (Vol. 1). Rio de Janeiro, RJ: Ed. 34 . 2 a edição

Deleuze, G. \& Guattari, F. (2011) Mil Platôs: capitalismo e esquizofrenia (Vol. 2). Rio de Janeiro, RJ: Ed. 34. 2a edição

Ferigato, S.H.; Carvalho, S.R. (2011). Pesquisa qualitativa, cartografia e saúde: conexões. Interface - Comunicação, Saúde, Educação, 15(38), 663-676. https://dx.doi.org/10.1590/S1414-32832011005000037

Franco, B.; Merhy, E.E. (2012) Cartografias do Trabalho e Cuidado em Saúde. Revista Tempus Actas de Saúde Coletiva. 6 (2) p.151-163 https://doi. org/10.18569/tempus.v6i2.1120

Franco, T. B. (2006) As Redes na Micropolítica do Processo de Trabalho em Saúde. In: Pinheiro R. e Mattos R.A. (Orgs.), Gestão em Redes: práticas de avaliação, formação e participação na saúde. Rio de Janeiro: CEPESC-IMS/ UERJ-ABRASCO

Godoy, A.M. (2014) Caracterização do trabalho em equipe no cotidiano dos serviços. - Atenção Psicossocial: conceitos, diretrizes e dispositivos clínicos. In: Processo de trabalho nos serviços de atenção a usuários de álcool e outras drogas. Recuperado de: https://unasus.ufsc.br/alcooleoutrasdrogas/

Guimarães, T. A. A.; Rosa, L. C. S. (2019) O Social em Questão. Ano XXII - no 44 - 111 -138. Recuperado de: http://osocialemquestao.ser.puc-rio.br/ media/OSQ_44_art5.pdf

Heimann, L.S., Ibanhes, L.C., Boaretto, R.C. \& Kayanoet, J (2010) A relação público-privado e o pacto pela saúde: novos desafios para a gestão em saúde. In: Santos \& Amarante (orgs) Gestão Pública e Relação Público Privado na Saúde. Rio de Janeiro: (EBES

Ipojuca, Secretaria de Saúde. (2011) Projeto Terapêutico Institucional do Centro de Atenção Psicossocial Gregório Bernardo.

Kastrup, V., \& Passos, E. (2014). Cartografar é traçar um plano comum. In Passos, E., Kastrup, V., \& Tedesco, S. Pistas do método da cartografia: experiência da pesquisa e o plano comum. Porto Alegre: Sulina.

Lobosque, A. M. (2007). CAPS: laços sociais. Mental, 5(8), 53-60. Recuperado de: http://pepsic.bvsalud.org/scielo.php?script=sci_arttext\&pi$d=\$ 1679-44272007000100004 \&$ lng $=p t \& t \operatorname{lng}=p t$.

Mattoso, A. (2013) Ipojuca: passado, presente, futuro do Municipio que mais cresce em Pernambuco. Recife. Carpe Diem Edições e Produções.

Merhy, E.E. (2004) Perspectivas atuais do SUS e o agir Tecnológico do trabaIhador como um ato ético-político. Serviço Social \& Saúde, 3 (3), 1-94. https://doi.org/10.20396/sss.v3i1.8634992

Merhy, E. E. (2002) Saúde: a cartografia do trabalho vivo. São Paulo: Hucitec.

Milhomem, M., \& Oliveira, A. (2007). O Trabalho em Equipe nos Centros de Atenção Psicossocial-CAPS. Cogitare Enfermagem, 12(1), 101-108. doi: http://dx.doi.org/10.5380/ce.v12i1.8277

Passos, E., \& Benevides de Barros, R. (2012). A cartografia como método de pesquisa -intervenção. In Passos, E., Kastrup, V., \& Escóssia, L. (Orgs.) Pistas do método da cartografia: Pesquisa-intervenção e produção de subjetividade. Porto Alegre: Sulina.

Pinafo, E., Carvalho, B. G., Nunes, E. F. P. A. (2016). Descentralização da gestão: caminho percorrido, nós críticos e perspectivas. Ciência \& Saúde Coletiva, 21(5), p.1511 - 1524. https://dx.doi.org/10.1590/141381232015215.18942015.

Rinaldi, D.L, \& Bursztyn, D. C. (2008). 0 desafio da clínica na atenção psicossocial. Arquivos Brasileiros de Psicologia, 60(2), p.32-39. Recuperado de http://pepsic.bvsalud.org/scielo.php?script=sci_arttext\&pi$d=\$ 1809-52672008000200005 \&$ lng $=p t \& t \operatorname{lng}=p t$.

Rotelli F, Leonardis O, Mauri D. (1990) Desinstitucionalização. São Paulo: Hucitec 